\title{
A PUBLICIDADE NOS ANOS JK: CONSUMO DE MERCADORIAS E IDEIAS NO NACIONAL- DESENVOLVIMENTISMO.
}

\section{Raquel Elisa Cartoce ${ }^{1}$}

RESUMO: Através da análise de anúncios publicitários veiculados nas revistas Manchete e $O$ Cruzeiro durante o período de governo de Juscelino Kubitschek (1956-1961), busca-se neste trabalho compreender as representações políticas, sociais, econômicas e as implicações ideológicas que eles produzem e em meio às quais são produzidos, na época do boom da industrialização do Brasil e - não por coincidência - da profissionalização da nossa publicidade. Para uma compreensão mais aprofundada deste processo, empreendo aqui um estudo de caso, observando como o tratamento da temática do trabalho nestes anúncios faz parte do desenvolvimento de uma determinada mentalidade a este respeito que se fixa e se expande para diversas áreas da nossa vida, tanto na esfera pública como na privada.

Palavras-chave: História da propaganda; Nacional-desenvolvimentismo; Representações políticas.

\section{Publicidade e industrialização: as duas faces da mesma moeda.}

São muitos os anúncios publicitários veiculados ao longo dos anos que ficam na memória de cada um de nós e na memória coletiva. Seja em filmes comerciais, páginas de revistas, traseiras de ônibus ou estações de metrô, estes anúncios colocam diante dos nossos olhos produtos os mais

${ }^{1}$ Graduanda do $5^{\circ}$ ano do curso de História da FFLCH / USP (Universidade de São Paulo). Fez iniciação científica recentemente sob orientação do prof. dr. Marcos F. Napolitano de Eugênio, cujos estudos deram origem a este artigo. Link do lattes: http://buscatextual.cnpq.br/buscatextual/visualizacv.do?id= K4322018J2 


\section{Cadernos de Clio, Curitiba, n. ${ }^{\circ}$ 4, 2013}

variados, e a constante possibilidade de que os tenhamos. Suas mensagens leves, divertidas ou muitas vezes emocionantes procuram eufemizar o objetivo primário do anúncio publicitário: estimular o consumo do produto anunciado, ampliando-se assim seus mercados e os lucros de quem o fabrica. Afinal, sabemos que o capitalismo, para se reproduzir, necessita que a produção sempre aumente - não só a de bens, como a de tecnologias que possibilitem um aumento ainda maior na produção, assim por diante - e que, em contrapartida, é necessário que se consuma cada vez mais para suprir essa produção.

Se estimular este consumo, abrir mercados e vender produtos ou serviços é a tarefa mais visível da publicidade, ao nos determos um pouco mais em suas mensagens, percebemos que os recursos comumente utilizados ocultam uma outra função ainda mais importante: ao convencer o indivíduo de que ele necessita - direta ou indiretamente - daquela mercadoria, criando assim determinadas necessidades e desejos, ela categoriza a vida e o universo, sendo assim uma forma de controle social. É ela quem diz o que é necessário, o que é belo, o que é bom, o que torna nossa vida melhor. Deste modo podemos dizer que a publicidade não vende apenas um produto, mas ela vende muito mais que isso.

O antropólogo Everardo Rocha explica melhor:

Se compararmos o fenômeno do "consumo" de anúncios e o de produtos, iremos perceber que o volume de "consumo" implicado no primeiro é infinitamente superior ao do segundo. O “consumo” de anúncios não se confunde com o "consumo” de produtos. Em cada anúncio “vende-se” “estilos de 
Cadernos de Clio, Curitiba, n. ${ }^{\circ}$ 4, 2013

vida”, “sensações”, “emoções”, “visões de mundo”, “relações humanas”, “sistemas de classificação”, “hierarquia” em quantidades significativamente maiores que geladeiras, roupas ou cigarros. Um produto vende-se para quem pode comprar, um anúncio distribui-se indistintamente. (Rocha, 1990: 27)

Podemos dizer que a publicidade é, portanto, uma metamercadoria (Borba, 1985). Porém, este processo de criação de determinadas significações e distinções do produto e de quem o consome é essencial não apenas para corroborar certas hierarquias ou status sociais inerentes ao capitalismo - ainda que isso seja muito importante -, mas é apenas parte de uma lógica ainda maior. Ao dar ao produto anunciado características próprias ao humano (personalidade, carisma, luxúria etc.), e lhe dando poderes mágicos - ou seja, fetichizando-o -, igualando assim o mundo dos objetos e o mundo dos homens, a publicidade omite os processos objetivos de produção daquela mercadoria e a história social do produto.

Assim, se temos a clássica formulação de que no capitalismo o humano é reificado através do processo de alienação (a separação do trabalhador do resultado de seu trabalho), a publicidade faz o caminho inverso: humaniza a coisa - a mercadoria -, camuflando o processo primeiro de reificação e exploração do homem.

Vemos então que a publicidade é um elemento essencial na sustentação do capitalismo, e claramente no capitalismo industrial e suas formas posteriores. Não é por coincidência que ela profissionalize-se justamente em momentos de forte crescimento industrial. Na Europa este 


\title{
Cadernos de Clio, Curitiba, n. ${ }^{\circ}$ 4, 2013
}

processo ocorreu durante o século XIX, quando além das grandes fábricas surgiram também as primeiras agências publicitárias, inicialmente vinculadas a elas, e depois autônomas administrativamente (Atem, 2009: 25). Assim, no momento em que uma enorme variedade de mercadorias passa a ser produzida em série, há a necessidade de um crescente mercado consumidor que as absorva. Para isso, a publicidade passa a ter os desejos (ilimitados), e não mais as necessidades (limitadas) como foco:

\begin{abstract}
A publicidade sugestiva abrandaria o valor objetivo do produto (seu valor-de-uso), considerado muito seco, pouco sedutor ou persuasivo, por apontar para as necessidades mais do que para os desejos. Isso levou à exploração da identidade das marcas, mais do que a simples exposição dos produtos (gradualmente, um maior peso no valor simbólico). De informativa a publicidade se tornava persuasiva. Os publicitários deveriam transformar consumidores potenciais em consumidores efetivos. (Atem, 2009: 27)
\end{abstract}

No Brasil, o processo é semelhante: ao longo das primeiras décadas do século XX o Brasil começava a se industrializar, especialmente na cidade de São Paulo, tendo uma indústria nacional mais voltada ao consumo interno (manufaturas, indústria têxtil e alimentícia) e também recebendo algumas importantes empresas estrangeiras, como a Nestlé, a GM e a Colgate. Conjuntamente, nasce na mesma cidade a primeira agência de publicidade brasileira, A Eclética (1914), que apesar de ser a pioneira, seria ofuscada pela chegada de duas grandes agências estadunidenses vindas com as empresas: o departamento de propaganda da GM em 1926 
e a (até hoje) poderosa J. W. Thompson em 1929, ambas obedecendo aos padrões técnicos da publicidade norte-americana. (Pinho, 1998: 13-17).

Ao longo da primeira metade do século XX, no entanto, o Brasil viveu momentos políticos e econômicos bastante conturbados. A crise de 1929, o movimento de 1930, a guerra de 1932, a ditadura iniciada em 1937, a II Guerra Mundial entre 1939 e 1945 e o suicídio de Getúlio Vargas em 1954 foram fatores importantes para que a o processo de industrialização se desse com certa precariedade, caracterizando-se, grosso modo, pela substituição de importações, então prejudicadas especialmente pela depressão do pós-guerra, e pela complementação das indústrias já existentes, principalmente de tecelagem e bens de consumo não duráveis, como aponta Paul Singer. (Singer, 1995: 217)

Em meio à grande crise política desencadeada pelo suicídio de Vargas, surge então o nome de Juscelino Kubitschek para ocupar a presidência, o que de fato ocorre. Muito da sua vitória se deve às suas duas grandes bandeiras: manter as instituições democráticas - uma tarefa bastante difícil num contexto em que até mesmo a sua posse só é garantida por um "golpe preventivo" - e promover o desenvolvimento econômico através de algo até então não utilizado sistematicamente pelos governantes: planejamento. (Gomes, 2002: 12)

Sob o slogan “50 anos em 5”, JK lança então o Plano de Metas, com o intuito de industrializar, integrar e modernizar o país, gerando o tão almejado progresso - palavras tão em voga à época. Pelo Plano de Metas, o Estado promoveria as bases para a industrialização através de setores estratégicos e pouco lucrativos, como infraestrutura, energia e 


\section{Cadernos de Clio, Curitiba, n. ${ }^{\circ}$ 4, 2013}

estradas, enquanto as empresas privadas (geralmente de capital internacional), beneficiadas pelas bases implantadas, produziriam os bens de consumo - principalmente bens duráveis, como automóveis e eletrodomésticos. Com esse projeto JK deixa clara a sua dúbia política, ao mesmo tempo nacionalista (com o controle de setores estratégicos) e alinhada com o capitalismo do auge da Guerra Fria (Moreira, 2003:161). A síntese e parte visível e palpável deste ambicioso projeto está na construção de Brasília, tida como uma utopia, que integraria todo o país e seria o grande símbolo da modernidade e do progresso brasileiros pelos traços de Lúcio Costa e Oscar Niemeyer.

Assim, é durante o governo JK que o Brasil sofre o grande boom da industrialização, em que ela é colocada - pela primeira vez - acima dos interesses da produção cafeeira, ou seja, como um projeto políticoeconômico hegemônico (porém, de modo algum absoluto). (Moreira, 2003). Simultaneamente, é nesta época que a publicidade brasileira se profissionaliza de fato. Alguns anos antes, em 1951, surge a Escola de Propaganda do MASP (que em 1978 torna-se a ESPM, ganhando o reconhecimento de ensino superior), cujos professores são os profissionais atuantes nas agências citadas, como a Thompson e o departamento de propaganda da GM, e cujos primeiros formandos atuarão justamente no período JK. (Ramos; Marcondes, 1995: 53-54). Reparemos com isto que a fundação de uma publicidade profissional nacional não apagará a influência estadunidense sobre o modo de fazer publicitário, mas a mantém, sendo uma via direta de expressão do American Way of Life no plano dos imaginários. 
Cadernos de Clio, Curitiba, n. ${ }^{\circ}$ 4, 2013

É então nos anos 50 que, no Brasil, se dá esta passagem de uma publicidade informativa para uma publicidade persuasiva. Dois anúncios da Kolynos, veiculados em $O$ Cruzeiro e Manchete com alguns anos de distância, demonstram esta diferença:

O primeiro, publicado em 1956 (O Cruzeiro, 7/7/1956: 62), traz um desenho em preto e branco de uma moça sorridente segurando uma escova de dentes, sobreposta a um relógio, com o seguinte texto em destaque: "1 minuto com Kolynos lhe dá essa proteção extra contra as cáries essa sensação extra de frescor... graças à exclusiva espuma de Ação Anti-Enzimática”, e ainda um texto em fonte menor com mais comentários. É, portanto, um texto basicamente informativo, que explica como age o produto e quais são os seus efeitos e sensações - ainda que estas sejam subjetivas. Já o segundo anúncio [Fig. 01] (Manchete, 5/11/1960: 48), veiculado quatro anos depois, tem várias diferenças em relação ao anterior. A primeira é de ordem técnica: o anúncio já é todo colorido e utiliza-se a foto em lugar do desenho, tornando a peça muito mais atrativa. Além disso, quase não há texto, sendo a foto de um homem sorridente na piscina o elemento central. Isso implica que toda a mensagem que era passada em um texto inteiro no primeiro anúncio, está agora contida na imagem (a ideia de sensação de frescor trazida pela piscina) e em apenas duas letras: “Ah...”. Assim, a função de proteção contra as cáries (plano da necessidade) perde espaço para a ideia sensação de frescor, e algo ainda a mais: o slogan "gente dinâmica pre 
Cadernos de Clio, Curitiba, n. ${ }^{\circ}$ 4, 2013

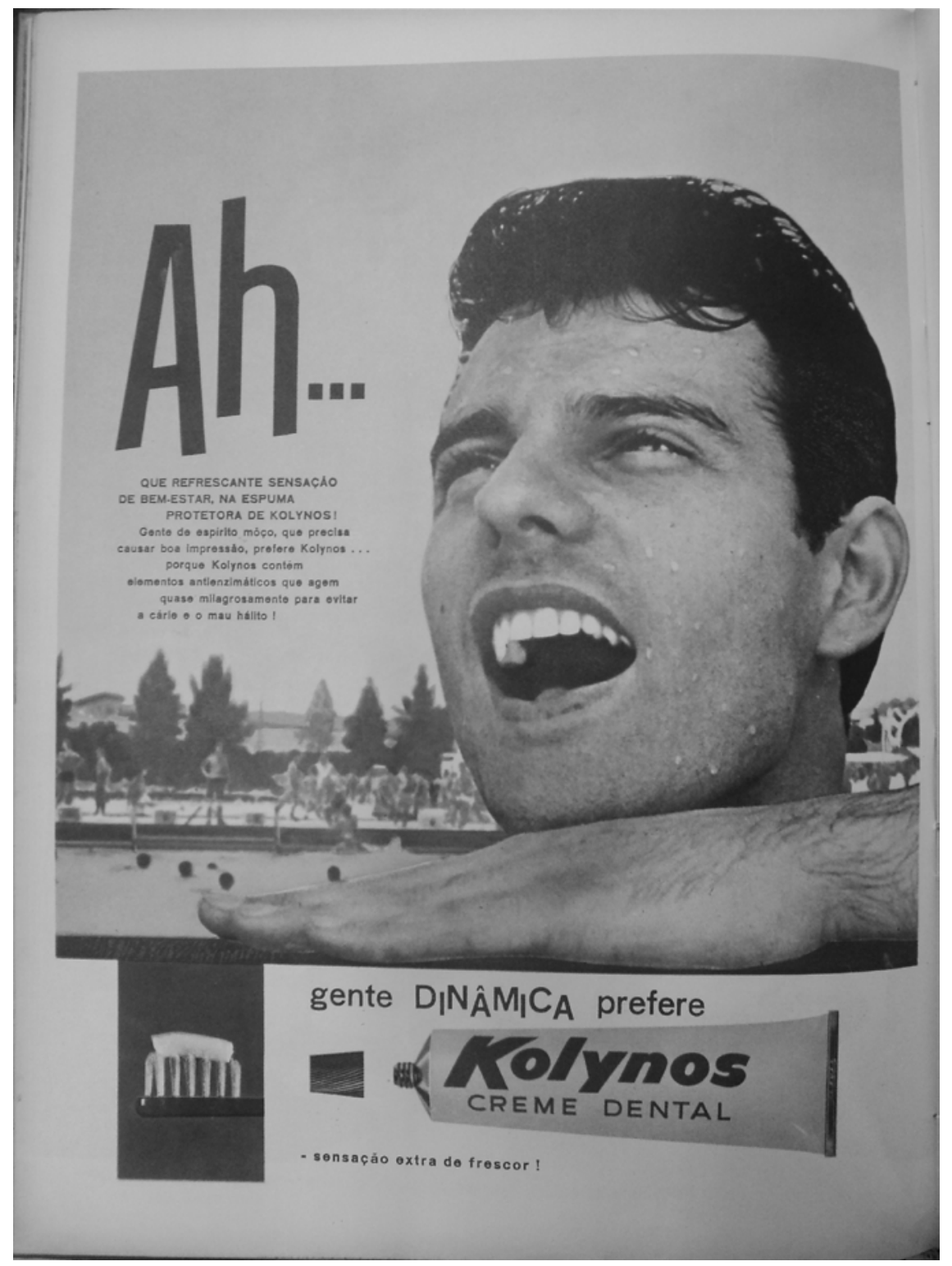

[Fig. 01] (Manchete, 5/11/1960: 48) 
Cadernos de Clio, Curitiba, n. ${ }^{\circ}$ 4, 2013

fere Kolynos”, reforçado pelo texto, dá ao produto uma característica além daquelas que até então lhe eram imputadas - o dinamismo. Aqui, atendendo o plano do desejo, o anúncio dá ao produto uma característica humana desejável, retransmitindo-a ao consumidor. Podemos formular então que gente dinâmica prefere Kolynos porque Kolynos confere dinamismo ao seu consumidor.

Resta perguntarmo-nos para quem o dinamismo é uma característica desejável, ou seja, de onde vem esta caracterização. Aqui está o mecanismo de dominação social de que falava Everardo Rocha, que também podemos traduzir como um mecanismo ideológico ${ }^{2}$, apresentado sempre de modo natural e universal.

Esta constituição da publicidade, no entanto, ainda não era tão clara nos anos 50. Nem tanto para os publicitários, que pouco formulavam isto teoricamente à época, e menos ainda ao público alvo dos anúncios. Por isso, os anunciantes (as revistas veiculadoras e as associações de agências de propaganda) sentiram a necessidade de esclarecer ao leitor

2 Segundo Célio Borba, pela análise de um excerto da Ideologia Alemã, de Marx, "O conceito de ideologia só pode ser concebido, neste tipo de sociedade, como um processo em que sistemas de representação de grupos sociais que, detendo a hegemonia num determinado momento histórico, procuram a adesão dos outros grupos sociais às suas concepções.” (Borba, 1985: 18). Mais à frente acrescenta: "O caráter da ideologia, como respeito à experiência de vida, significa que a ideologia não se apresenta como um sistema individualizado de idéias cujos contornos sejam facilmente delimitados, ao contrário, permeia as relações sociais, ao mesmo tempo que penetra em todas as atividades dos homens. Está presente nas concepções dos homens acerca da realidade social, na sua visão de mundo em geral, nos seus costumes, gostos, atitudes e, na sociedade capitalista, está penetrada pela estrutura da mercadoria, e suas implicações, como elementos naturais, eternamente dados.” (Borba, 1985: 20) 


\section{Cadernos de Clio, Curitiba, n. ${ }^{\circ}$ 4, 2013}

do que se tratavam essas propagandas que invadiam as páginas das revistas, veiculando alguns anúncios explicativos, dentre os quais destaco um (Manchete, 1/12/1956: 11), no qual temos a figura de uma dona de casa que questiona: “Mas afinal, que faz a propaganda pelo povo?”. A resposta da Associação Paulista de Propaganda traz inicialmente as respostas mais evidentes e perceptíveis, como o aumento do lucro das empresas e vantagens trazidas para o consumidor pela concorrência por ela provocada. No entanto, conjuntamente a estas funções pretensamente objetivas, o texto destaca ainda outras:

(...) educa o povo em hábitos de mais confôrto e segurança, ensina coisas úteis, provoca desejos, ambições... estimula o trabalho, a vontade de vencer, eleva o nível de vida!

A Propaganda é a grande fôrça do mundo moderno: seu maior sonho é ver o dinheiro na mão de todos, o cônforto no lar de todos, o bem-estar e a segurança, o desenvolvimento e o progresso espalhados a todos ver os homens felizes, os homens comprando e comprando satisfeitos, pra serem cada vez melhores, cada vez mais ricos!

Aqui o discurso escancara o objetivo de um grupo - dos publicitários e daqueles a quem servem (os capitalistas), ou seja, da classe dominante - de propor determinados valores como universais e imutáveis, desejáveis a todos e desejados por todos. Um grupo que procurava se firmar diante de uma sociedade que se transformava radicalmente naquele momento sob diversos aspectos. Era o capitalismo que buscava fixarse não apenas economicamente no Brasil, mas nos imaginários, nas re- 
Cadernos de Clio, Curitiba, n. ${ }^{\circ}$ 4, 2013

presentações e nas visões de mundo de uma população que saía em massa dos campos em busca de nova vida nas grandes cidades. Esta fixação é condição necessária para a sua reprodução e sobrevivência.

A análise dos anúncios divulgados nas revistas Manchete e O Cruzeiro $^{3}$ - as de maior tiragem do veículo de comunicação mais eficiente da época, já que conseguia chegar a todos os cantos do país e a uma maior abrangência de camadas sociais, posto que não suas mensagens não são efêmeras como as do rádio, mas podem passar de mão em mão por um longo período de tempo - levou-me perceber os diversos modos como a ideologia capitalista, aqui implantada sob o projeto nacionaldesenvolvimentista de JK, vai se entranhando nos imaginários, produzindo-os e reproduzindo-os concomitantemente, procurando naturalizar certos valores e práticas sociais, culturais e políticas.

Entre diversas e interessantíssimas peças publicitárias que permitem compreender como estes valores e práticas se inserem no tecido social, seleciono aqui algumas que demonstram mais claramente o papel político e ideológico desempenhado pela publicidade no contexto de afirmação do capitalismo industrial no Brasil através o projeto nacionaldesen-volvimentista de JK. Papel este perfeitamente resumido por Jean Baudrillard:

${ }^{3}$ Em função do pouco espaço disponível, não será discutido aqui o papel das revistas neste processo, já que se pode considerá-las um suporte para as fontes principais deste trabalho: os anúncios publicitários. Vale apenas notar que Manchete (1952) surgiu posteriormente a O Cruzeiro (1928), caracterizando-se por grandes inovações técnicas e gráficas, que também influenciaram a produção e a veiculação dos anúncios nesta publicação. 
Cadernos de Clio, Curitiba, n. ${ }^{\circ}$ 4, 2013

De fato, a publicidade não omite tão cuidadosamente os processos objetivos, a história social dos objetos senão para, através da instância social imaginária, melhor impor a ordem real de produção e de exploração. (...) é uma instância imaginária que se adapta a você, enquanto que, em troca, você se adapta a uma ordem bem real. (...) Vemos por aí o imenso papel político que desempenham a difusão dos produtos e as técnicas publicitárias: asseguram adequadamente a substituição das ideologias anteriores, morais e políticas. Melhor ainda: enquanto que a integração moral e política não se exercia sem problemas (necessitava lançar mão da repressão aberta), as novas técnicas economizam repressão: o consumidor interioriza, no próprio movimento do consumo, a instância social e suas normas. (Baudrillard, 2002: 184-185)

Dentre o universo de temáticas trabalhadas nos anúncios da época que são de extrema relevância para a compreensão deste processo, como uma certa noção de progresso justificadora deste modelo, o crescimento da indústria automobilística, o uso da imagem de Brasília e sua inserção na ideia de modernidade em contraste com o arcaísmo, o lugar da mulher na sociedade e várias outras, optei por analisar mais detidamente aqui uma temática essencial para a compreensão mais ampla, não apenas de eventos concernentes a esta época, mas de um processo que ganha força neste momento e que tem duração mais longa e mais profunda nas nossas mentalidades, consistindo num perfeito caso do que teorizaram Baudrillard e os outros autores aqui trabalhados: o mundo do trabalho. 


\section{Produção e consumo, reificação e fetichização.}

Tendo em vista que o Governo JK e suas estruturas estão estreitamente atrelados à consolidação do capitalismo nos moldes dos EUA, ou seja, que a formação de um imaginário social eminentemente capitalista em certa medida transcende as representações políticas nacionais, estando ambos em parte subordinados a esta estrutura econômica, destaco primeiramente como se dá nos anúncios publicitários o processo de fetichização da mercadoria em contraposição à reificação do homem, condição para que o capitalismo se fixe definitivamente, como já visto.

Este anúncio da Coca-cola [Fig. 02] (Manchete, 7/5/1960: contracapa externa) é bastante revelador. O consumo do refrigerante é posto como ideal para o momento de pausa das tarefas porque assim "Todo o trabalho é prazer e rende mais”. Ou seja, esses produtos são como combustíveis para o trabalhador, e não é à toa que haja um frasco de óleo com certo destaque nesta peça: se o óleo é o combustível da engrenagem, a Coca-Cola é o combustível da “engrenagem” da operária. De modo semelhante, a Nestlé coloca em seu anúncio um operário tomando uma xícara de Nescafé em seu momento de descanso (O Cruzeiro, 3/3/1956: 41), argumentando que assim ele pode fiscalizar o trabalho dos fusos “com o melhor de sua competência e atenção”.

Assim, o trabalhador não é mais do que mais uma peça destas máquinas, que faz parte das suas engrenagens e não tem mais relação alguma com o que produz, estando alienado dele e cumprindo apenas seu papel em um determinado momento da produção. 


\section{Cadernos de Clio, Curitiba, n. ${ }^{\circ}$ 4, 2013}

A genialidade de Charles Chaplin na criação da memorável cena das máquinas em Tempos Modernos, na qual o personagem Carlitos é uma grande vítima deste processo, consegue extrair uma deliciosa poesia de algo sem poesia nenhuma, que é cruamente representado em um anúncio das fitas Scotch (O Cruzeiro, 6/9/1958: 37). Nele temos um personagem que trabalha na vedação de uma fileira de caixas com a fita da marca. A singularidade está neste personagem: é impossível definir se se trata de um homem-máquina ou de uma máquina-homem. Independentemente da ordem, a verdade é que é exatamente isso o que se busca: trabalhadores que sejam o mais semelhante possível a máquinas: eficientes e obedientes.

Há, no entanto, o outro lado. Se no universo das máquinas a condição humana é retirada do trabalhador, é pelo consumo que esta condição é retomada. Pelo anúncio da Coca-Cola, o consumo do refrigerante traz o prazer ao trabalho, ou seja, supostamente refaz o laço perdido entre o homem e o trabalho, no qual há uma identidade entre o trabalhador e o objeto produzido. Esta relação, no entanto, é deformada, pois a identidade não se dá com o que foi produzido, mas com o que foi consumido.

Assim, a publicidade se põe como uma mediação entre o mundo selvagem da produção capitalista e o mundo da identidade do consumo, cuja linguagem “cala o produto e fala do bem de consumo” (Rocha, 1990: 67). Ausenta-se assim a sociedade real e suas contra-dições, e o trabalho da operária torna-se prazeroso por que simplesmente é omitido o processo de exploração de seu trabalho e daquele que produziu a CocaCola que ela está tomando. 
Cadernos de Clio, Curitiba, n. ${ }^{\circ}$ 4, 2013

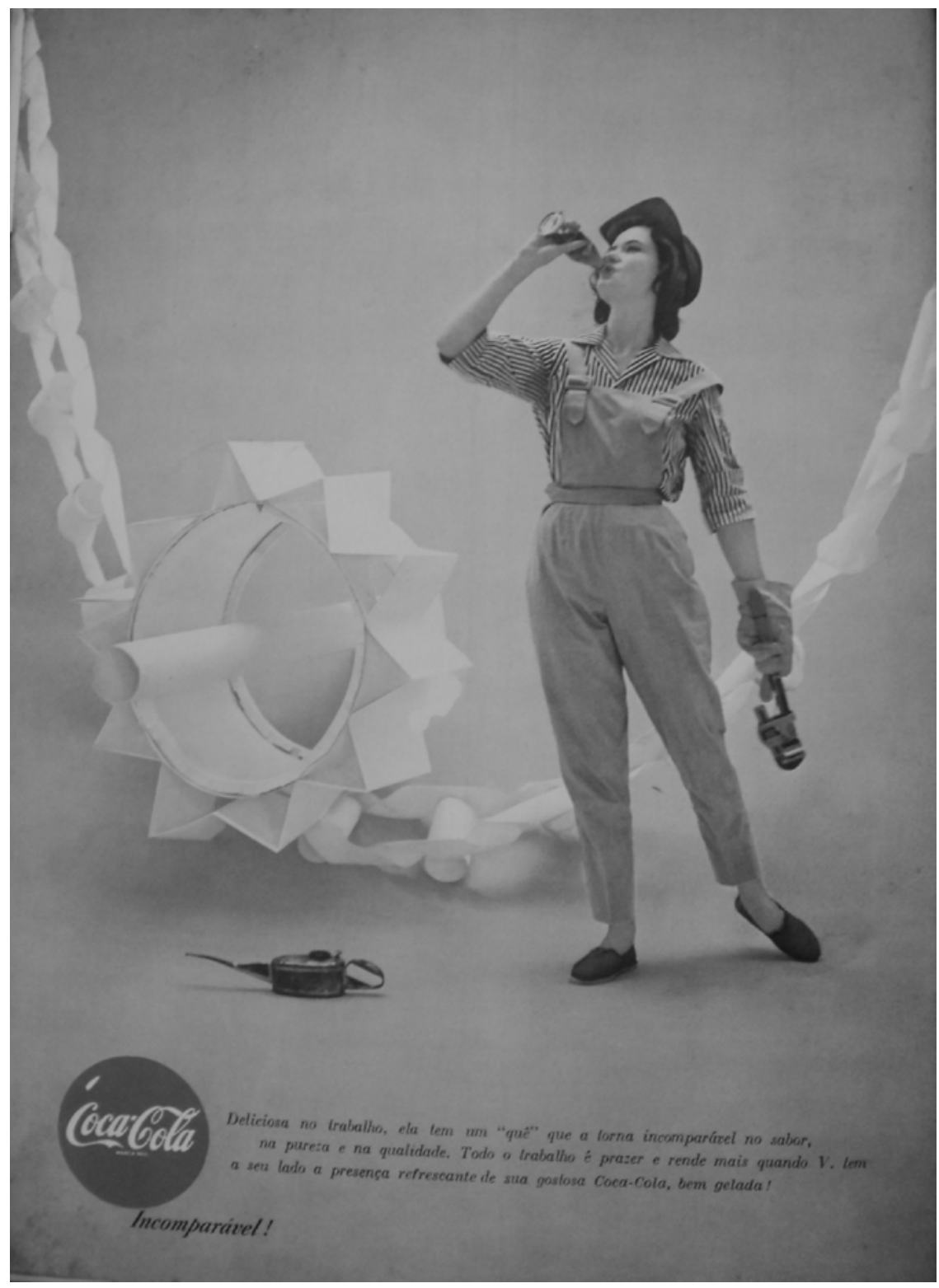

[Fig. 02] (Manchete, 7/5/1960: contracapa externa) 
Cadernos de Clio, Curitiba, n. ${ }^{\circ}$ 4, 2013

\section{Movimentos populacionais: trabalho e consumo.}

A necessidade de criar esta idealização do mundo do trabalho industrial e das possibilidades de um novo padrão de consumo que ele supostamente traz é especialmente forte neste período: sendo os anos 50 a época do grande boom da industrialização brasileira, é também neste período que as cidades do Sudeste, onde localizam-se as maiores indústrias, recebem um enorme contingente de novos operários, a maioria vinda de regiões rurais, especialmente do Nordeste.

Um tanto negligenciado pela nossa historiografia, o intenso movimento migratório ocorrido nesta época provocou enormes transformações no Brasil, de modo que em 1960 quase metade da população brasileira já vivia nas cidades ${ }^{4}$.

Eric Hobsbawm explica “a morte do campesinato” em quase todo o globo durante a segunda metade do século XX (dando destaque a este processo no chamado Terceiro Mundo) a partir da modernização e maquinização da agricultura, além de outras realizações tecnológicas no campo. Segundo ele, "Nessas circunstâncias, a agricultura simplesmente não mais precisava dos números de mãos e braços sem os quais, nos dias pré-tecnológicos, uma safra não podia ser colhida, nem na verdade do número de famílias camponesas regulares e seus empregados permanentes.” (Hobsbawm, 1995: 287)

Um anúncio do Jeep Willys ( $O$ Cruzeiro, 6/9/1958: capa interna) ratifica e ilustra exemplarmente o texto de Hobsbawm. O "braço direito do homem do campo" (O Jeep) substitui um contingente enorme de bra-

${ }^{4}$ Cf. dados dos Censos de 1950 e 1960. (Apud. DURHAN, 1973: 21). 
Cadernos de Clio, Curitiba, n. ${ }^{\circ}$ 4, 2013

ços que ali trabalhavam anteriormente, destacando-se na foto apenas o motorista sobre o veículo e outro operário que carrega recipientes de leite a ser vendido. Este processo de industrialização da agricultura é de fato fundamental na expulsão de um número imenso de famílias do campo, mas há no Brasil uma peculiaridade que agrava tal processo: a desordenada ocupação de novas terras ao Oeste por latifúndios, advinda da política de completa omissão do governo JK em relação a esta questão como moeda de troca pela hegemonia dos industriais -, também expulsa diversos pequenos proprietários e posseiros dessas regiões. (Moreira, 2003)

Porém, se temos as principais explicações para a expulsão de populações rurais, devemos procurar compreender o que as atrai para as cidades. O motivo mais visível é, certamente, a grande oferta de emprego pelas indústrias. No entanto, esta não é a única razão. Para Eunice Durhan,

A migração rural-urbana também pode ser considerada como um fenômeno de mudança sociocultural que envolve a transformação dos padrões de comportamento vigentes nas comunidades rurais de onde provêm os imigrantes. Esses padrões representam uma forma particular de ajustamento a um contexto geográfico-sociocultural determinado e precisam ser substituídos por outros, que permitam uma adaptação satisfatória às condições urbanas de vida. (Durhan, 1973: 11) 
Cadernos de Clio, Curitiba, n. ${ }^{\circ}$ 4, 2013

Assim, “É nos anos 1950 que pela primeira vez na história do Brasil o mundo urbano sobrepuja o rural em termos de imaginário da sociedade brasileira.” (Oliveira, 2002: 31). Ou seja, não apenas a expansão do modo de produção capitalista para o campo, mas também do modo de vida da cidade são os responsáveis por esta gigantesca alteração na estrutura social brasileira. Enfim, “A vida da cidade atrai e fixa porque oferece melhores oportunidades e acena um futuro de progresso individual, mas também porque é considerada uma forma superior de existência.” (Mello; Novais, 1998: 574)

Aqui se compreende com clareza a citação de Baudrillard feita anteriormente acerca de uma “economia” de repressão e violência quando essa substituição de valores e práticas é tragada para o plano individual do consumo. No caso que analisamos, a difusão de bens de consumo vindos das indústrias (junto às suas imagens publicitárias) e da correlata ideia da cidade como lugar superior e, portanto, civilizador, faz com que o indivíduo que sai do campo com conhecimentos, ações e valores tradicionais, abandone-os em prol do modo de vida urbano, pautado na eficiência, na obediência e no individualismo. Assim, este próprio indivíduo se educa para tornar-se mais uma peça (muito barata) das engrenagens das fábricas, no anseio de galgar os degraus da hierarquia social e poder também consumir tudo aquilo que vê e deseja. Forma-se assim um operariado muito mais obediente e maleável que aquele das primeiras décadas do século, politizados e com solidariedade de classe, posto que o trabalho ainda não era individualizado pelo fordismo.

No entanto, ainda que o contingente de migrantes no Brasil dos anos 50 seja enorme, nas inúmeras imagens dos anúncios publicitários 
Cadernos de Clio, Curitiba, n. ${ }^{\circ}$ 4, 2013

analisados estes personagens praticamente não existem, com apenas uma exceção que será trabalhada mais adiante. E o motivo é simples: ainda que estas pessoas desloquem-se em direção às cidades em busca do modo de vida e do padrão de consumo que ouvem no rádio, veem nas revistas e nos seus anúncios, este continuará não sendo o seu mundo.

A despeito da ilusão capitalista da igualdade de oportunidades, sabemos que “a situação de partida é sempre desigual, porque o próprio capitalismo, a própria concorrência, entre empresas e entre homens, recria permanentemente assimetrias entre os homens e as empresas.” (Mello; Novais, 1998: 581-2) Assim, com algumas exceções, estes migrantes ocuparão os postos de trabalho subalternos e de baixa qualificação, nos quais também as possibilidades de consumo são bem menores.

Desta forma, por mais que os anúncios publicitários, via de regra, se dirigissem a camadas médias e altas, tendo-as como personagens e interlocutoras, também as classes baixas consomem estes anúncios (no sentido dado por Everardo Rocha): não podem comprar a maioria daqueles produtos, dos quais muitas vezes são até mesmo concorrentes ${ }^{5}$, mas compartilham do desejo de obtê-los e aos seus significados sociais. Enfim, compartilham desta ideologia e enquadram-se nela.

A única peça publicitária encontrada entre o material pesquisado que trata da questão da migração, ainda que de modo indireto, é bastante representativa. O anúncio da FNM (Fábrica Nacional de Motores) [Fig.

${ }^{5}$ Cf. a análise de Anna Cristina Figueiredo de alguns anúncios do início da década de 60, como o do aspirador de pó Walita, que "não recusa serviço", do carro Renault-Dauphine, que era "de inteira confiança” e da televisão Empire, “a melhor babá do mundo!” Figueiredo, 1998: 68-71) 
Cadernos de Clio, Curitiba, n. ${ }^{\circ}$ 4, 2013

03] (Manchete, 29/10/1960: 107) fala de "um dos construtores de Brasília”, o caminhão da marca. No entanto, no fim do texto aparece outro personagem, coletivo, que tem bastante destaque na figura: os Candangos, operários da construção da nova capital. O texto diz que “O famoso Fenemê, como é conhecido pelo povo em todas as estradas do Brasil, portou-se valentemente, lado a lado com os candangos, atestando a capacidade realizadora de uma Nação que desperta.”.

O anúncio, portanto, aponta uma união de forças entre a indústria e as próprias mentalidades em prol desta “nação que desperta”. Mas podemos nos questionar se estes próprios trabalhadores também compartilhavam deste desejo de colaboração com o crescimento da Nação. Um interessante documento é capaz de nos fornecer uma pista, ainda que a partir dele não se possa tirar uma conclusão generalizada: em 2011 foi descoberto um fosso no Congresso Nacional com registros provavelmente feitos pelos próprios candangos em 1959, durante a construção de Brasília. Estas mensagens mostram uma forte presença de valores tradicionais, como honra e honestidade, através de escritos como "Si todos Brazileiros Focem Diginos de honra e honestidade, Teriamos um Brazil bem melhor!”, mas já atrelados ao pensamento dominante de que o projeto nacional-desenvolvimentista de JK - representado em Brasília - solucionaria os problemas do país, registrado na expressão "Brazilia de Hoje, Brasil Amanhã”. Enquanto pairava sobre boa parte da população brasileira a ideia de que o futuro havia finalmente chegado e o Brasil se tornava um país desenvolvido, estes trabalhadores têm plena consciência de que em todo este ufanismo do progresso e da modernidade eles não se encaixavam. No entanto, isso não quer dizer que não compartilhavam deste ufa- 
Cadernos de Clio, Curitiba, n. ${ }^{\circ}$ 4, 2013

nismo, que então é transferido novamente para o futuro: "Sò Temos uma Esperança Nos Brazileiros de Amanhã” ${ }^{\text {. }}$

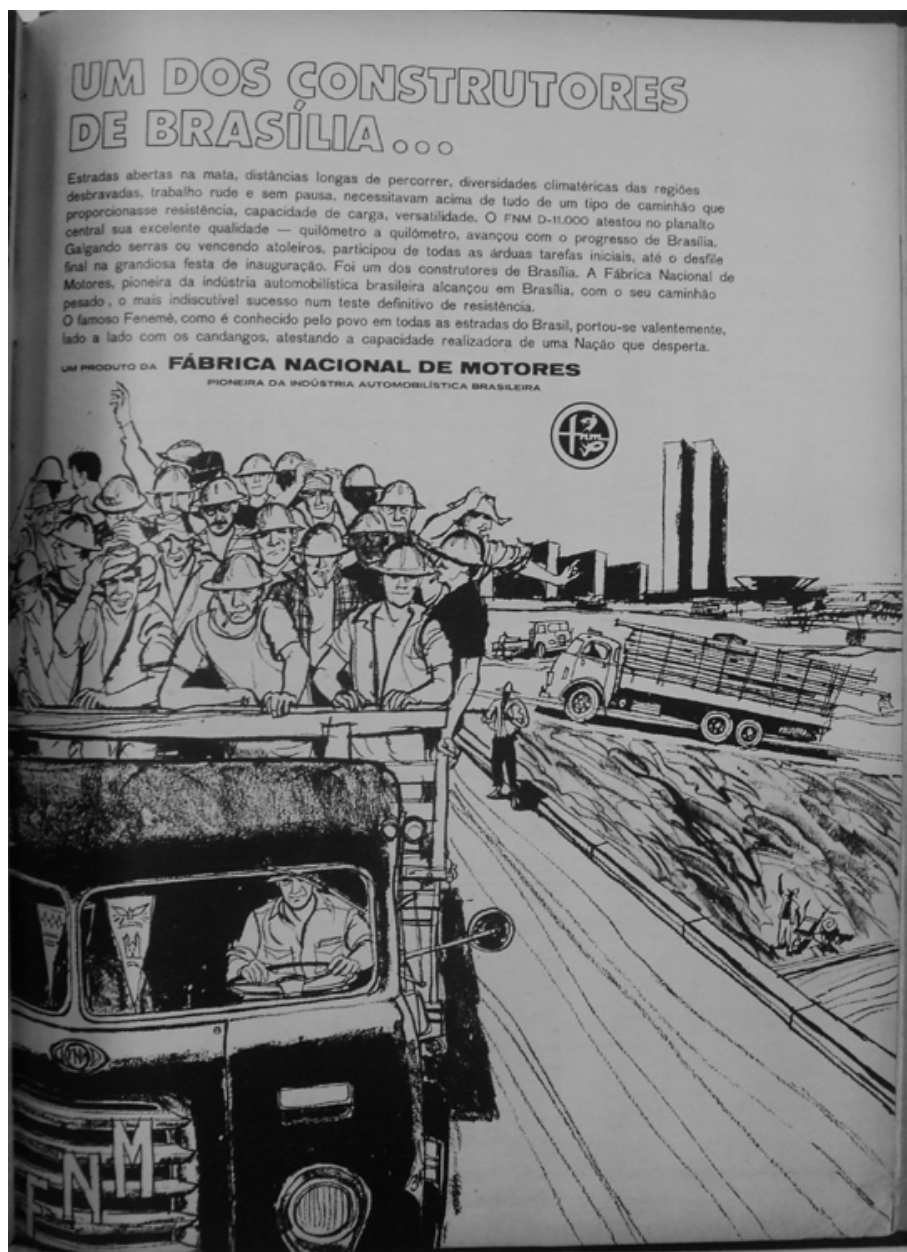

[Fig. 03] (Manchete, 29/10/1960: 107)

6

Expressões transcritas de fotos deste fosso, publicadas em http://noticias.uol.com.br/cotidiano/ultimas-noticias/2011/08/11/inscricoes-detrabalhadores-que-construiram-brasilia-sao-descobertas-no-congresso.htm Foto de André Coelho/ Agência O Globo [Acesso em 21.set.2012] 
Cadernos de Clio, Curitiba, n. ${ }^{\circ}$ 4, 2013

A partir disto, podemos inferir que há uma consciência por parte do operariado em relação à exploração por eles sofrida (não se devendo esquecer dos importantíssimos movimentos de resistência de trabalhadores urbanos e rurais, além de outras categorias), que no entanto muitas vezes é cooptada e entendida como necessária para a posterior inserção no sistema. Inserção que se dá sob uma ilusão de igualdade de oportunidades, em que basta o esforço pessoal e uma boa “autopropaganda” para se alcançar o posto desejado: o de possibilidades ilimitadas de consumo.

\section{O progresso do país e o progresso individual.}

Com a inserção no mundo urbano, o desejo de "crescer na vida” se torna cada vez mais recorrente pelas possibilidades de melhores colocações profissionais trazidas pelas grandes indústrias e empresas e tudo o que gira em torno disso. "Progredir na vida”, portanto, passa a referir-se exclusivamente a um crescimento de ganho material e às possibilidades de demonstrar tal ganho através do poder de consumo.

Posto que o produto resultante do trabalho do indivíduo já está totalmente desvinculado dele, como já vimos, o prestígio do cargo ocupado e o salário ganho passam a ser o objetivo do trabalho, e não mais o trabalho em si, desprovido de qualquer sentido. Este prestígio e o salário a ele concernente seguem o padrão capitalista de eficiência e concorrência. Porém, frequentemente é acrescentado mais um valor: o da aparência.

Em ambientes onde as pessoas se conhecem cada vez menos, inclusive no trabalho, a boa aparência passa a ser um valor altamente desejável, sendo cada vez mais a responsável pelo julgamento do indivíduo e do seu trabalho. Conforme Anna Figueiredo, “a ascensão social deixa de 
Cadernos de Clio, Curitiba, n. ${ }^{\circ}$ 4, 2013

ser conquistada apenas pelo esforço ou pelo talento do indivíduo e passa a depender, em grande medida, do seu padrão de consumo.” (Figueiredo, 1998: 96)

É seguindo essa lógica que a Gillette publica nas duas revistas estudadas uma sequência de anúncios protagonizados por diversos tipos de trabalhadores - um comerciário, um bancário, um estudante, um funcionário, um operário e um jogador de futebol - que tem duas coisas em comum: usam Gillette e, especialmente, buscam maior prestígio e/ou salário em seu trabalho. Um objetivo conquistado pela simpatia, destacada em todos os anúncios da série, mas principalmente pelo consumo do produto anunciado: “A razão do meu sucesso? 'Está na cara’ faço a barba todo dia com Gillette azul...”, é o que dizem todos os personagens. Um dos textos ainda acrescenta: "Sim! A simpatia é meio caminho para o sucesso. Vença também pela simpatia, conservando boa aparência.” (O Cruzeiro, 3/3/1956: 68)

A busca cada vez maior por posições privilegiadas na sociedade através de certas colocações no mundo do trabalho, agora determinadas pelos critérios de eficiência e aparência, e sob as leis da concorrência, não atinge apenas os trabalhadores em suas atividades, mas inclusive as profissões em si. Se tradicionalmente os ofícios mais cobiçados eram os ligados ao exercício intelectual e científico, como o direito, a medicina e o magistério, tais valores foram sucumbindo a esta crescente necessidade de quadros puramente técnicos e racionalizados.

Ao fazerem um panorama da estrutura social brasileira e sua mobilidade nos anos 50, Fernando Novais e João Cardoso de Mello ressaltam que 
Cadernos de Clio, Curitiba, n. ${ }^{\circ}$ 4, 2013

A grande empresa privada passou a exigir um novo padrão de direção e de gestão, mais racionalizado, mais profissionalizado. Com isso, firma-se de vez a valorização do engenheiro, que despontara no começo do século como símbolo da civilização urbanoindustrial, em oposição ao bacharel. (...) As diretorias, gerências e chefias vão se especializando, se multiplicando. Surgem as escolas de administração de empresas, clubes de gerentes e revistas especializadas, que tratam de difundir os padrões americanos de gestão. E vai aparecendo o profissional da publicidade, também no mais puro molde americano, junto com a escola de propaganda. (Mello; Novais, 1998: 593)

Não é por um acaso, portanto, que a Parker 51, “a caneta mais desejada do mundo”, esteja nas mãos de um Engenheiro, num anúncio da marca (O Cruzeiro, 28/1/1956: 42-E). Segundo o texto da peça, "Êle prefere a Parker ' 51 ', porque sabe que é uma obra prima de engenharia, um instrumento de precisão, que jamais decepcionará.”. Assim, num mundo que exige cada vez mais “funcionalidade” e “precisão”, o papel do engenheiro (e do bem de consumo que aqui o representa) é vital, não podendo causar “decepções”.

Longe de ser uma coincidência, o Plano de Metas de JK contém 30 itens, dos quais 5 são referentes ao setor de energia, 7 aos transportes, 6 à alimentação (ampliação de produção e armazenamento), 11 à indústria de base e automobilística e apenas uma (a última) à educação. Esta meta diz: “Meta 30 - Pessoal técnico: Intensificação da formação de pessoal técnico e orientação da educação para o desenvolvimento.” (Apud. Faro; Silva, 2002: 84). 
Cadernos de Clio, Curitiba, n. ${ }^{\circ}$ 4, 2013

Este elemento nos ajuda a perceber com clareza a composição desta difícil trama dos anos JK: a implantação de um projeto internacional de consolidação definitiva do capitalismo no então chamado terceiro mundo, inclusive o Brasil, em meio à disputa da Guerra Fria e de seus valores, se expressa aqui na política de JK de intensa aceleração da industrialização (que internamente joga com os setores ruralistas) sem que haja uma real transformação social, o que é expresso na sua política educacional posta na meta $\mathrm{n}^{0}$ 30, de uma completa despreocupação com uma formação ampla do indivíduo e o puro objetivo de formar quadros técnicos pras indústrias e mesmo para o Estado que se burocratizava. Longe de se chocar com as representações sociais (especialmente das crescentes camadas médias) acerca da formação pessoal e profissional do indivíduo, tal projeto encontrou respaldo no próprio desejo de ascensão social através deste tipo de profissão, acalentado - ainda que de modo bem mais tímido - desde o início da industrialização.

\section{Considerações finais: que democracia?}

Enfim, o uso da publicidade como documento para o estudo dos anos JK se mostra bastante fecundo se consideramos que industrialização e profissionalização da publicidade não são apenas processos coincidentes, mas que o primeiro necessita do outro como difusor não apenas de mercadorias, mas de determinadas ideias, valores e práticas - ou, em suma, da ideologia - do capitalismo industrial.

Ideologia que atrai um sem-número de pessoas que viviam miseravelmente no campo, no sertão ou em pequenas cidades, em busca de um novo padrão de vida - e de consumo -, que fornece a eles uma vida não 


\section{Cadernos de Clio, Curitiba, n. ${ }^{\circ}$ 4, 2013}

menos miserável nas grandes cidades, agora inchadas e sem infraestrutura nas periferias, onde passam a morar estas pessoas; que explora seu trabalho e os aliena do que produzem, tirando-lhes completamente o sentido do trabalho; que, finalmente, torna a vida do indivíduo tão ou mais miserável quanto anteriormente, mas que oculta esta miséria - muitas vezes mais moral do que financeira - nas ilusões de progresso e de livre iniciativa, nas ilusões de consumo interminável e insaciável.

O que subjaz nisto é uma falsa ideia de democracia implantada nos anos JK e que tem sobrevivido muito bem até hoje: apesar da valorização dos Anos JK como um dos períodos mais democráticos vividos no Brasil, os “Anos Dourados”, pouco se questiona se houve (e se há) a democratização do processo de industrialização, dos espaços do campo e da cidade, dos bens produzidos e do enorme capital gerado em tudo isso. Uma falsa democracia que se esconde pelo nascimento, neste período, de uma "democracia de mercado”. Se a nossa democracia nunca foi plena, se os direitos dos cidadãos e mesmo humanos não são plenos, o "direito do consumidor” ganha cada vez mais espaço, junto a uma publicidade cada vez mais requintada, com maior destaque no cenário mundial e mais presente em nosso quotidiano.

Como afirma Guilherme Atem,

Sob uma aparente interface amigável de democracia, jaz uma “democracia de mercado”, tão sedutora quanto redutora. Em outras palavras, uma “democracia de mercado” é uma contradição nos próprios termos e jamais deveria se basear numa participação restrita daqueles que nela têm poder aquisitivo para consumir. 
Cadernos de Clio, Curitiba, n. ${ }^{\circ}$ 4, 2013

É claro que a exclusão socioeconômica continua afetando a maior parte das pessoas, mas o novo Capitalismo encontrou um novo modo de dominar a todos os que não são miseráveis, sem que eles se sintam agredidos - a dominação pela inclusão (via consumo). (...) A nova inclusão tornou-se a chave para a nova sujeição. (Atem, 2009: 28)

“Democracia de mercado” que se mostra em pleno vigor até hoje ainda que tenha tomado diferentes formas ao longo do tempo, em conjunturas específicas -, e cuja compreensão passa pelo entendimento da escolha de um determinado modelo de desenvolvimento e modernização, feita de modo definitivo nos anos JK.

\section{Referências das Fontes}

Revista “O Cruzeiro” - Ano 28: $n^{\circ} 15$ [28.01.1956]; n 20 [03.03.1956]; n 62 [07.07.1956]. Ano 30: $\mathrm{n}^{\circ} 47$ [06.09.1958].

Revista “Manchete" - $n^{\circ} 241$ [01.12.1956]; $n^{\circ} 420$ [07.05.1960]; $n^{\circ} 445$ [29.10.1960]; nº 446 [05.11.1960].

\section{Referências Bibliográficas}

ATEM, Guilherme. "Persuadere: Uma história social da propaganda.” In: MACHADO, Maria Berenice (Org.) Publicidade e Propaganda - 200 anos de história no Brasil. Novo Hamburgo/RS: Feevale, 2009.

BAUDRILLARD, Jean. O sistema dos objetos. 4. ed. São Paulo: Perspectiva, 2002.

BORBA, Célio Cavalcanti. Publicidade: Uma metamercadoria - análise da ideologia do discurso publicitário impresso no Brasil. Recife: Mestrado UFPE, 1985.

CAPELATO, Maria Helena R.; DUTRA, Eliana R. F. Representação política. O reconhecimento de um conceito na historiografia brasileira. IN: CARDOSO, 


\section{Cadernos de Clio, Curitiba, n. ${ }^{\circ}$ 4, 2013}

Ciro Flamarion; MALERBA, Jurandir. (Orgs.) Representações: contribuição a um debate transdisciplinar. Campinas/SP: Papirus editora, 2000.

DURHAN, Eunice R. A caminho da Cidade. São Paulo: Perspectiva, 1973.

FARO, Clovis de; SILVA, Salomão L. Q. da. "A década de 1950 e o Programa de Metas.” IN: GOMES, Angela de Castro (Org.). O Brasil de JK. Rio de Janeiro: Editora FGV, 2002.

FIGUEIREDO, Anna Cristina Camargo Moraes. "Liberdade é uma calça velha, azul e desbotada" - Publicidade, cultura de consumo e comportamento político no Brasil (1954-1964). São Paulo: Hucitec, 1998.

GOMES, Angela de Castro (Org.) O Brasil de JK. Rio de Janeiro: Editora FGV, 2002.

HOBSBAWM, Eric. Era dos Extremos: O Breve século XX: 1914-1991. 2. ed. São Paulo: Companhia das Letras, 1995.

MELLO, João M. Cardoso de; NOVAIS, Fernando A. "Capitalismo tardio e sociabilidade moderna.” IN: SCHWARCZ, Lilia M. (Org.) História da vida Privada no Brasil, v. 04. São Paulo: Companhia das Letras, 1998.

MOREIRA, Vânia Maria Losada. "Os anos JK: industrialização e modelo oligárquico de desenvolvimento rural.” IN: FERREIRA, Jorge; DELGADO, Lucilia de A. (Orgs.) O Brasil Republicano, v.3. Rio de Janeiro: Civilização Brasileira, 2003.

OLIVEIRA, Lúcia Lippi. "Tempos de JK: a construção do futuro e a preservação do passado.” IN: MIRANDA, Wander Melo (Org.). Anos JK: Margens da modernidade. São Paulo: Imprensa Oficial/ Rio de Janeiro: Casa de Lucio Costa, 2002.

PINHO, José B. “Trajetória da Publicidade no Brasil: das origens à maturidade técnico-profissional.” IN: (org.) Trajetória e questões contemporâneas da publicidade brasileira. 2. ed. São Paulo: INTERCOM, 1998.

ROCHA, Everardo P. G. Magia e Capitalismo: um estudo antropológico da publicidade. 2. ed. São Paulo: Brasiliense, 1990.

SINGER, Paul. "Interpretação do Brasil: Uma experiência histórica de desenvolvimento.” IN: FAUSTO, Boris (coord.) História geral da civilização brasileira - Tomo III: O Brasil Republicano, v. 4. 3. ed. Rio de Janeiro: Bertrand Brasil, 1995. 